\title{
Micropoderes no cotidiano do trabalho de enfermagem hospitalar: uma aproximação do pensamento de Foucault
}

\author{
Micro-powers in the daily work of hospital nursing: an approximation to the thinking of Foucault \\ Micropoderes en el cotidiano del trabajo de enfermería hospitalaria: una aproximación del \\ pensamiento de Foucault
}

Silvio Arcanjo Matos Filho'; Norma Valéria Dantas de Oliveira Souza"'; Francisco Gleidson de Azevedo Gonçalves"I', Ariane da Silva Pires ${ }^{\prime V}$; Thereza Christina Mó Y Mó Loureiro Varellav.

\begin{abstract}
RESUMO
Objetivos: discutir e analisar os micropoderes existentes no cotidiano do trabalho de enfermagem hospitalar, de acordo com o pensamento de Foucault. Conteúdo: o ponto de partida é a análise histórica da divisão do trabalho, na área hospitalar e da enfermagem, em que se evidenciam características comuns aos conceitos de micropoderes discutidos por Foucault. Constata-se a existência de padrões de comportamento e disciplina na atuação da enfermagem hospitalar que são compatíveis com os pressupostos teóricos foucaultianos. Conclusão: é necessário aprofundamento das discussões sobre esta temática com intuito de ampliar o entendimento acerca da prática profissional da enfermagem hospitalar, bem como estabelecer mecanismos que possibilitem a análise pelos trabalhadores de seu cotidiano visando à transformação de posturas e comportamentos. São necessários mobilização e envolvimento coletivo para que processos de mudança aconteçam nas relações de poder que permeiam a profissão de enfermagem.

Descritores: Enfermagem; trabalho; hospitais; pensamento de Foucault.
\end{abstract}

\section{ABSTRACT}

Objectives: to examine and discuss micro-powers in the daily work of hospital nursing, in the light of the thinking of Foucault. Content: the point of departure was a historical analysis of the division of labor at hospitals and in nursing, which evidenced features in common with the concepts of micro-powers discussed by Foucault. Patterns of behavior and discipline were found to exist in the practice of nursing that are compatible with Foucault's theoretical assumptions. Conclusion: this issue needs to be discussed in greater depth for a broader understanding of the professional practice of hospital nursing, as well as to establish mechanisms that enable workers to examine their daily activities with a view to modifying postures and behavior. Mobilization and collective involvement are also necessary for processes of change to take place in the power relations that permeate the nursing profession.

Descriptors: Nursding; work; hospitals; Foucault's thought.

\section{RESUMEN}

Objetivos: discutir y analizar los micropoderes existentes en el cotidiano del trabajo de enfermería hospitalaria, de acuerdo con el pensamiento de Foucault. Contenido: el punto de partida es el análisis histórico de la división del trabajo, en el área hospitalaria y de la enfermería, en que quedan evidentes las características comunes a los conceptos de micropoderes discutidos por Foucault. Se constata la existencia de patrones de comportamiento y disciplina en la actuación de la enfermería hospitalaria que son compatibles con los presupuestos teóricos foucaultianos. Conclusión: es necesario profundizar las discusiones sobre esta temática con el propósito de ampliar el entendimiento acerca de la práctica profesional de la enfermería hospitalaria, así como establecer mecanismos que posibiliten que los trabajadores hagan el análisis de su cotidiano con vistas a la transformación de posturas y comportamientos. Se apunta, además, la necesidad de movilización e implicación colectiva para que procesos de cambio ocurran en las relaciones de poder que impregnan la profesión de enfermería.

Descriptores: Enfermería; trabajo; hospitales; pensamento de Foucault.

\section{INTRODUÇÃO}

O filósofo francês, Michel Foucault, é autor de inúmeros trabalhos que seguiam uma linha estruturalista, entretanto, sua narrativa de contraponto às ideias de verdade, objetividade e razão, sobretudo com a publicação de Microfísica do Poder $^{1}$ (1979) e Vigiar e Punir ${ }^{2}$
(1987), passa a configurar-se como um representante contemporâneo do pós-estruturalismo. Tal categorização deve-se ao fato de o conjunto das obras explicitarem que os mecanismos de poder são exercidos fora, abaixo e ao lado do aparelho de Estado, assim como problematizarem

Enfermeiro. Mestre. Aluno do Curso Doutorado em Enfermagem. Professor Adjunto da Universidade Estadual do Sudoeste da Bahia. Brasil. E-mail: silviohgpv@gmail.com "Enfermeira. Doutora. Professora Associada, Faculdade de Enfermagem, Universidade do Estado do Rio de Janeiro. Brasil. E-mail: norval souza@yahoo.com.br '"Enfermeiro. Mestre em Enfermagem. Faculdade de Enfermagem, Universidade do Estado do Rio de Janeiro. Brasil. E-mail: gleydy_fran@hotmail.com vEnfermeira. Mestre em Enfermagem. Professora Assistente, Faculdade de Enfermagem, Universidade do Estado do Rio de Janeiro. Brasil. E-mail: arianepires@oi.com.br

vEnfermeira. Doutora. Professora Adjunta, Faculdade de Enfermagem, Universidade do Estado do Rio de Janeiro.Brasil. E-mail: thereza1208@gmail.com 
que a relação de poder e saber nas sociedades modernas tem como objetivo produzir verdades, cujo interesse essencial é a dominação do homem por meio de práticas políticas e econômicas de uma sociedade capitalista.

Poder é um termo que se originou do latim possum, que significa ser capaz de, direito de deliberar, agir e mandar e, também, dependendo do contexto, a faculdade de exercer a autoridade, impor obediência, a soberania, ou o império de dada circunstância. Segundo a sociologia, poder é a habilidade de impor a sua vontade sobre os outros mesmo que haja resistência, sendo exercido em diversos campos a exemplo do poder social, o poder econômico, o poder militar, o poder político, poder público, entre outros ${ }^{3}$.

O poder constituiu-se como um dos assuntos que permearam, de forma bastante intensa, a obra de Foucault, sendo abordado de uma forma ou de outra, em quase todos os seus escritos.

Ao longo dos anos, as relações de poder entre os integrantes da equipe de enfermagem e da medicina podem ser retratadas nos discursos sobre a verdade do binômio doença/doente, ou do trabalho manual/ intelectual. O saber/poder da medicina esteve sempre relacionado com uma narrativa de verdade focalizada na doença e num trabalho considerado intelectual, em detrimento do saber da enfermagem, avaliada como predominantemente manual e centrada na promoção da saúde, sobretudo, no campo hospitalar 4 .

Faz-se fundamental frisar que saber e poder guardam uma relação intrínseca. O saber não é neutro; tem caráter político, na medida em que a constituição de um determinado saber traz agregado um sentido de poder. Instituições como a escola, a prisão, o hospital, ao longo dos anos, têm legitimado o poder instituído ${ }^{5}$.

A histórica supremacia médica nas organizações hospitalares exemplifica bem a relação entre saber e poder. As atribuições de diagnóstico, indicação de terapia, realização de exames, internação e alta hospitalar conferem ao profissional médico um poder político institucional. Em contraponto, a enfermagem, numericamente a maior categoria nestas organizações, cujo saber implica atribuições na qualidade e segurança do cuidado e diminuição dos riscos da assistência prestada, ainda tem baixa acumulação de poder nas instituições, em que pesem os avanços em sua autonomia.

O modelo Taylorista-Fordista de organização do trabalho em saúde, em especial na enfermagem hospitalar, com marcante divisão entre o trabalho intelectual e trabaIho manual, entre enfermeiros e técnicos de enfermagem, revela a relação de poder no interior desta categoria ${ }^{6,7}$.

Este modelo de organização, seja em instituição pública ou privada, transmite relações de poder entre aqueles que prescrevem o trabalho e aqueles que executam, seja entre categorias profissionais ou dentro de uma mesma categoria como o que acontece na enfermagem, na qual o enfermeiro planeja a assistência e os técnicos desenvolvem suas ações atreladas ao planejamento.

É importante destacar que a problemática da divisão social e técnica do trabalho de enfermagem tem raízes históricas, pois Florence Nightingale, ao lançar as bases da enfermagem moderna, instituiu que o trabalho de enfermagem seria desenvolvido por nurses - que fariam o trabalho manual de higienização e desenvolvimentos de outras técnicas menos complexas - e lady nurses - que fariam a tarefa intelectual de supervisão, planejamento, avaliação. As lady nurses eram de camadas sociais mais abastadas e tinham refinada educação; em contrapartida, as nurses advinham de estratos sociais bem menos privilegiados, com pouca educação e trato social ${ }^{8}$.

Tal divisão social e técnica, acabou por nublar a visão do público em geral e da mídia sobre a profissão de enfermagem, por não verem com clareza as atribuições e responsabilidades de cada componente dessa categoria profissional. E, nesse sentido, há um forte desconforto por parte dos enfermeiros quando são confundidos pela mídia ou pelos usuários, principalmente, em relação a algum fato que desprivilegie ou macule a imagem do enfermeiro ${ }^{9}$.

No ambiente hospitalar, a figura centralizadora do médico é quem domina a atividade produtiva e detém, relegando aos demais profissionais da saúde um papel de coadjuvante, uma vez que o modelo assistencial é o biomédico, centrado na terapêutica medicamentosa e cirúrgica. Essa hegemonia médica determina na visão dos demais profissionais da saúde e do paciente, que o enfermeiro pareça estar aquém do conhecimento necessário nas terapêuticas de saúde, o que é uma inverdade ${ }^{10}$.

De acordo com a contextualização teórica abordada e com base nos escritos de Foucault, Microfísica do Poder $^{1}$ e Vigiar e Punir ${ }^{2}$, e autores que fizeram releitura de suas obras, ${ }^{5,11,12}$ este estudo teve como objetivo discutir e analisar os micropoderes existentes no cotidiano do trabalho de enfermagem hospitalar, de acordo com o pensamento de Foucault.

\section{O Poder e A Organização Hospitalar}

A história da criação dos hospitais mostra que estas instituições, até o século XVIII, eram locais destinados a abrigar pessoas pobres que estavam morrendo e, para isso, tais edificações eram construídas em locais distantes da cidade com a finalidade de segregação e exclusão, objetivando proteger as outras pessoas do contágio, tendo em vista o desconhecimento da etiologia e formas de transmissão das enfermidades ${ }^{1}$.

Sua principal função era a de proporcionar o isolamento e o confinamento das pessoas doentes, visando muito mais a proteção dos que estavam fora dos hospitais do que o atendimento aos pacientes, de tal forma que a Igreja Católica se configurava como a principal respon- 
sável pela expansão destas instituições que ostentavam, também, o caráter de orfanato, asilo e leprosário ${ }^{13}$.

A partir do século XVIII, ocorreu uma mudança na arquitetura hospitalar, cujos edifícios passaram a ser construídos no espaço urbano, em forma de pavilhões, com evolução do espaço físico, implicando melhoria da circulação de pessoas, também em termos de separação dos leitos, no isolamento dos doentes mais graves, de modo que a arquitetura hospitalar passou a ser um mecanismo de cura, caracterizando-se como: "um instrumento de cura de mesmo estatuto que um regime alimentar, uma sangria ou um gesto médico"1:108.

Na perspectiva de Foucault, quando o hospital ganhou tal concepção e a distribuição do espaço tornou-se um mecanismo terapêutico, o médico converteu-se no principal responsável pela organização hospitalar, com implantação de técnicas de poder disciplinar e intervenção sobre o meio.

Na Guerra da Crimeia, no séc. XIX, de maneira similar, Florence Nightingale introduziu a visão da atuação da enfermagem para além do paciente, ampliando o escopo de atuação ao ambiente nas funções de organizar os serviços de cozinha, lavanderia, rouparia, limpeza e almoxarifado, controlando-os pela observação e supervisão, e pela hierarquia e disciplina na enfermagem ${ }^{14}$.

Observa-se, no mundo contemporâneo, que "o hospital de hoje é uma organização social construída nas cidades, juntamente com as transformações tecnológicas do mundo do trabalho"15:47. Enfatiza-se igualmente que a chegada do hospital moderno propiciou a mudança do domínio da religiosidade para a racionalidade científica, a partir da qual o sistema de poder em seu interior passou a ser exercido pela categoria médica, que definiu a hierarquia do hospital e estabeleceu um sistema de registro permanente. Surgiu, assim, o hospital médico, centrado na relação individual médico e paciente, e baseado em técnicas de poder disciplinar e técnicas médicas de intervenção sobre o meio.

Tal intervenção tem nas suas relações resquícios d e padrões de comportamento e de disciplina ${ }^{15,16}$, observados no uso do jaleco branco e crachá pelos profissionais de saúde, na identificação dos leitos e prontuários, no controle dos equipamentos, materiais e medicamentos, horário de refeições e de visitas, passagem de plantão, distribuição de pacientes por patologias, na padronização dos lençóis e roupas dos pacientes; tudo isso vinculado ao poder/saber médico.

Na concepção Foucault lana, o poder é concebido como um conjunto de práticas sociais e discursos construídos historicamente que disciplinam o corpo e a mente de indivíduos e grupos, por isso tais comportamentos são edificados, incorporados e muito difíceis de serem suprimidos. Incorporar mudanças dentro desse sistema cultural de preceitos e de poderes estabelecidos é como mexer em suas características estáveis ${ }^{15}$.
Cabe ressaltar que o processo de trabalho hospitalar é definido como sendo do tipo "complexo e múltiplo, pouco articulado, com diferenciação e hierarquia entre os grupos profissionais envolvidos no processamento do trabalho e pelo discurso médico-hospitalar dominante sobre as partes do corpo"15:52.

A construção histórica do poder no interior das instituições hospitalares pode ser também observada no exercício da enfermagem. O enfermeiro possui o poder de coordenar os setores assistenciais, decidir onde e em que leito vai ficar o paciente, o horário do banho e do curativo, o local de guarda de materiais e medicamentos, a escala de serviço dos técnicos e auxiliares de enfermagem, o controle das chaves dos armários, condições que se traduzem em exercício de poder.

Estas práticas disciplinares, largamente disseminadas em escolas, exército, asilos, hospitais, e até mesmo nas empresas capitalistas, constituem-se em estratégias de poder que se transformam em práticas discursivas que disciplinam o corpo, instituindo gestos, atitudes, condutas e posturas; regulam a mente e ordenam as atitudes e comportamentos ${ }^{16,17}$. Assim, no mundo contemporâneo, o aumento da complexidade das organizações, bem como de sua importância para as sociedades, faz com que cresça, em consequência, a quantidade de estudos sobre o poder e suas relações no âmbito da teoria das organizações.

\section{Micropoderes E O TRABALHO DE ENFERMAGEM HOSPITALAR}

Ao analisar a situação atual do mundo do trabaIho, pode-se entender que a forma como a sociedade capitalista está organizada - social, econômica e politicamente - estabelece o controle dos meios de produção e da força de trabalho, aumentando as exigências sobre o trabalhador que, sob pressão, submete-se a situações no ambiente de trabalho geradoras de risco à sua saúde.

No Brasil, os profissionais de enfermagem, em especial os que trabalham em instituições hospitalares, têm reconhecidamente longas jornadas de trabalho. A escala de plantões permite que estes profissionais se dediquem a mais de uma atividade produtiva, o que pode levar à exaustão e consequente adoecimento, podendo ainda afetar a qualidade da assistência aos pacientes ${ }^{18}$. Além disso, os serviços no âmbito hospitalar apresentam um modelo organizacional hierarquizado e verticalizado, que mantém a centralização do poder, e hierarquia rígida ${ }^{19}$.

Esta centralização do poder na organização laboral não se dá por acaso, pelo contrário, ao sistema capitalista interessa o trabalhador subordinado ao poder hierárquico para cumprir as ordens e determinações em prol da produção, induzindo-o a pensar que produzindo mais, ganhará mais, e a manter-se com baixa capacidade de crítica e alienado pelo sistema. - 
Corroborando o pensamento marxista, evidencia-se que "o operário trabalha sob a inspeção do capitalista, o qual, ao comprar essa força de trabalho por um dia, uma semana, obtém em troca o direito de explorá-la durante um dia, uma semana"20:160.

O despotismo torna-se então mesclado com a manipulação do trabalho, com o envolvimento dos trabaIhadores, através de um processo ainda mais profundo de interiorização do trabalho alienado (estranhado). 0 operário deve pensar e fazer para o capital, aprofundando sua subordinação ao mesmo ${ }^{21}$.

Ademais, constata-se o poder de convencimento do capital, que faz com que o trabalhador acredite ser capaz de cumprir múltiplas tarefas e construir um imaginário de crescimento profissional ${ }^{22,23}$.

Tal poder confere às classes dominantes (ou campos dominantes) um capital simbólico, disseminado e reproduzido por meio de instituições e práticas sociais, que lhes possibilita exercer o poder como referendado na teoria bourdieusiana. Este é "um tipo de poder quase mágico, invisível, pois com ele se obtém o equivalente daquilo que é obtido pela força, sem, porém, fazer uso dela"24:982.

Nas organizações hospitalares, evidenciam-se os saberes articulados para o controle de corpos, ou seja, a disciplina como mecanismo de poder. Na enfermagem hospitalar, observa-se a disciplina aplicada na questão do cumprimento dos horários e na execução dos diversos procedimentos realizados pelos trabalhadores.

Na concepção foucaultiana, o objetivo do poder é ao mesmo tempo econômico e político, e, para isso, utiliza-se da disciplina para diminuir a resistência e tornar os homens dóceis politicamente; a disciplina fabrica corpos submissos e exercitados, corpos dóceis; a disciplina aumenta a força dos corpos (em termos econômicos de utilidade) e diminui seu potencial em termos políticos, ao determinar a obediência².

$\mathrm{Na}$ atuação da enfermagem hospitalar, percebe-se que o corpo tem que tirar força para suportar o cansaço físico e mental do dia a dia, além de se sujeitar ao poder econômico que impõe a cada dia um novo equipamento ou material a ser usado sob o argumento de ser o melhor para o paciente. Obedecer a normas administrativas, da Comissão de Controle de Infecção Hospitalar (CCIH), do Ministério da Saúde (MS), da Agência Nacional de Vigilância Sanitária (ANVISA) são mais exemplos de submissão na lógica do poder, com o agravante da impossibilidade de refletir criticamente sobre este processo de dominação.

Por esse motivo é que as relações de poder geram manifestações de resistências, expressas no subterfúgio a uma autoridade ou lei, nas estratégias de manipulação, nos silêncios, nas relações com os códigos morais. A subjetividade, por sua vez, seria a própria libertação, por meio do conhecimento do sujeito acerca dos mecanismos de poder ${ }^{25}$.
Assim, "a partir do momento em que existe relação de poder, há resistência em potencial, por isso somos aprisionados por uma forma homogênea de poder, já que os choques entre poder e resistências geram novas e infindáveis configurações de poder"26:120

No entanto, a teoria foucaultiana pretende demonstrar também que o poder não carrega unicamente pretensões repressivas, ou seja, seu aspecto negativo de intervenção, de arbitrariedade, de controle e submissão. Há também o poder positivo. "Temos que admitir que o poder produz saber; que poder e saber estão diretamente implicados"27:150.

O fato é que o poder é uma prática social constituída historicamente e que se manifesta em diversos níveis da sociedade e não é exercido apenas pelo Estado, mas também pelas instituições e pelas pessoas no cotidiano de suas relações.

Os saberes e fazeres foram edificados para manter o status quo, privilegiando a classe dominante em detrimento das necessidades sociais e de saúde da grande maioria da população do Brasil28.

\section{CONSIDERAÇÕES FINAIS}

O pensamento foucaultiano iluminou a análise da práxis da enfermagem como fazer histórico e com uma prática alicerçada em determinados contextos sociais, que estão diretamente envolvidas com o saber/poder médico e as relações de poder na sociedade como um todo, seja no âmbito social, político, cultural e econômico.

Recomenda-se que os membros da equipe de enfermagem busquem apreender o conhecimento produzido em torno da mudança organizacional e possam utilizá-lo para exercerem poder em determinadas áreas, podendo, assim, reconfigurar suas posições na arena política das organizações.

Aponta-se a necessidade de mobilização e envolvimento coletivo para que os processos de mudança aconteçam, pois cabe aos atores sociais, com todas as suas singularidades e interesses, não só a definição de prioridades, mas a construção de estratégias e mecanismos para a superação das contradições existentes no mundo do trabalho que alimentam as relações de poder.

\section{REFERÊNCIAS}

1. Foucault M. Microfísica do poder. Organização e tradução de Roberto Machado. Rio de Janeiro: Graal; 1984

2. Foucault M. Vigiar e Punir: nascimento da prisão. Tradução de Raquel Ramalhete. 27a ed Petrópolis (RJ): Vozes; 1987.

3. Brígido El. Michel Foucault: Uma análise do poder. Rev. Direito Econ. Socioambiental. 2013; 4(1): 56-75.

4. Lorenzetti J, Oro J, Matos E, Gelbcke. Organização do trabalho da enfermagem hospitalar: abordagens na literatura. Texto Contexto Enferm. 2014; 23(4): 1104-12.

5. Souza WL. Ensaio sobre a noção de poder em Michel Foucault. Rev. Múltiplas Leituras. 2011; 4(2):1-2.

6. Gonçalves FGA, Souza NVDO, Zeitoune RCG, Adame GFOL, Nascimento SMP. Impacto do neoliberalismo no trabalho hospi- 
talar de enfermagem.Texto Contexto Enferm. 2015; 24(3): 646-53. 7. Souza NVDO, Gonçalves FGA, Pires AS, David HMSL. Influência do neoliberalismo na organização e processo hospitalar de enfermagem. Rev. bras. enferm.(Online) 2017; 70(5): 961-9

8. Carlos DJD, Germano RM. Enfermagem: história e memórias da construção de uma profissão. REME rev. min. enferm. 2011; 15(4): 513-21.

9. Souza NVDO, Pires AS, Gonçalves FGA, Tavares KFA, Baptista ATP, Bastos TMG. Formação em enfermagem e o mundo do trabalho: percepções de egressos de enfermagem. Aquichan. 2017; 17(2): 204-16.

10. Avila LI, Silveira RS, Lunardi VL, Fernandes GFM, Mancia JR, Silveira JT. Implicações da visibilidade da enfermagem no exercício profissional. Rev. gaúcha enferm. 2013; 34(3): 102-9.

11. Borenstein MS. O poder disciplinar da enfermagem no espaço hospitalar: uma aproximação com o pensamento de Foucault. Rev. bras. enferm.(Online). 1999; 52(4): 583-8.

12. Ferreirinha IMN, Raitz TR. As relações de poder em Miche Foucault: reflexões teóricas. Rev. Adm. Public. 2010; 44(2): 367-83. 13. Nogueira ILS. A importância do ambiente físico hospitalar no tratamento terapêutico do paciente hospitalizado. Rev. Espec. On-line IPOG. 2015; 10(1): 09.

14. Catão MO. Genealogia do direito à saúde: uma reconstrução de saberes e práticas na modernidade [online]. Campina Grande (PB): EDUEPB; 2011.

15. Frello AT, Carraro TE. Contribuições de Florence Nightingale: revisão integrativa. Esc. Anna Nery. Rev. Enferm. 2013; 17(3): 73-9. 16. Santos PR. Saúde do trabalhador no trabalho hospitalar: metodologias integradas de avaliação de experiências nos espaço de intervenção em hospitais no Estado do Rio de Janeiro [tese doutorado]. Rio de Janeiro: Escola Nacional de Saúde Pública Sergio Arouca; 2010
17. Ferla AA, Oliveira PTR, Lemos FCS. Medicina e hospital. Fractal. Rev. Psicol. 2011; 23(3): 487-500.

18. Gonçalves FGA, Souza NVDO, Pires AS, Santos DM, D’Oliveira CAFB, Ribeiro LV. Modelo neoliberal e suas implicações para a saúde do trabalhador de enfermagem. Rev. enferm. UERJ. 2014; 22(4): 519-25.

19. Santos TM, Camponogara S. Um olhar sobre o trabalho de enfermagem e a ergologia. Trab. Educ. Saúde. 2014; 12(1): 149-63. 20. Barros NMG. Riscos de adoecimento: estudo com médicos e enfermeiros emergencialistas em um hospital mato grossense [dissertação mestrado]. Belo Horizonte(MG): Faculdade Novos Horizontes; 2012.

21. Deville G. O capital/Karl Marx. Tradução e condensação de Gabriel Deville. 3a ed. 2areimp. Bauru (SP): Ediopro; 2013.

22. Antunes R, Praun L. A sociedade dos adoecimentos no trabaIho. Serv. Soc. Soc. 2015; 123:407-27.

23. Antunes R. O socialismo, lutas sociais e novo modo de vida na América Latina. Rev. Direito Práx. 2017. 8(3):2212-26.

24. Pereira WR. Entre a dominação simbólica e a emancipação política no Ensino Superior em Enfermagem. Rev. Esc. Enferm. USP. 2011; 45(4): 981-8.

25. Fonseca JPA. Considerações sobre a constituição do sujeito do cuidado de si no pensamento de Michel Foucault. Veritas. 2012; 57(1): 143-52.

26. Costa E, Borenstein MS. O saber/poder dos enfermeiros e as transformações históricas (1971-1981): história da enfermagem. Rev. eletr. 2012; 3(2): 109-24.

27. Danner F. O Sentido da Biopolítica em Michel Foucault. Rev. est. filos. 2010; (4): 143-57.

28. Solano LC, Germano RM, Valença CN, Malveira FM. O corpo no processo ensino-aprendizagem a partir do paradigma da complexidade. Rev. enferm. UERJ. 2012; 20(3):399-403. 